\title{
Streamlining USDA Regulation of Gene Editing to Benefit US Agriculture
}

\author{
Sarah Hartman*, Wilson Horner*, Christopher Jackson*, \\ Emma Kovak*, Vetri Velan*
}

Science Policy Group at Berkeley, Berkeley, CA

http://doi.org/10.38126/ISPG170108

Corresponding author: ctjackson@berkeley.edu

*Indicates equal contributions

Keywords: gene editing; GMO; agriculture; regulation; USDA

\begin{abstract}
Executive Summary: Feeding a growing world population and adapting agricultural production to a changing climate is a significant challenge that can be mitigated through the use of new gene-editing technologies in crops. However, current regulatory processes are overly burdensome and confusing, limit scientific innovation, and unduly hinder the widespread production of genetically engineered crops. To address these shortcomings, we propose the consolidation of federal regulatory communication into the United States Department of Agriculture and a unified and detailed web platform for commercial approval applications.
\end{abstract}

\begin{abstract}
I. Gene editing: an evolving technology that could feed the world

Agricultural production is increasingly strained by changing climate and population growth. With the global population expected to reach 9.8 billion by 2050 , farmers will have to grow about $70 \%$ more food than current production (AFBF 2019). Meeting this challenge will require scientific advances that bridge the gap between conventional techniques and new technologies in plant breeding.
\end{abstract}

Selective breeding has been used for thousands of years in the domestication of crops to artificially select desired traits in foods, including those which enable higher yield. The basis for these traits is the organism's genome, which comprises all of the genes encoded in its DNA. When the DNA sequence of a particular gene is altered, this can change the physical expression of that gene-the organism's phenotype. Recent breeding techniques have used chemicals to induce random DNA mutations; these mutations may modify a trait of interest, such as increased drought tolerance or disease resistance, but often have additional, unwanted effects which may require decades to remove through breeding. Although such human-guided changes in traits deliberately alter the genetics of crops, they are not considered to be genetically engineered (GE) in the United States (US). US law more narrowly defines genetic engineering as "techniques that use recombinant, synthesized, or amplified nucleic acids to modify or create a genome" (APHIS 2020).

In the past decade, efforts to select for desirable plant traits have drastically increased with new biotechnology to more quickly and precisely introduce changes at the genetic level (Kuzma 2018). New gene-editing techniques like CRISPR-Cas9 have revolutionized the field, allowing plant breeders to target genes governing traits of value with greater speed and precision. In 2016, a report from the National Academies of Sciences, Engineering, and Medicine found no evidence that foods from GE crops are less safe than foods from non-GE crops (NAS 2016). Despite this, the new and evolving nature of gene-editing technology has placed a disproportionate regulatory burden on GE crops.

Because some genetic engineering techniques allow for the introduction of genes from other species, regulators want to ensure that changes to an organism's genome will not produce deleterious 
effects on human or environmental health. While the likelihood of such a risk is low, these crops are subject to more regulation than chemically mutagenized crops. The USDA justifies this differential regulation based on breeding technique because "plants created through conventional breeding have a history of safe use related to plant pest risk" (APHIS 2020).

With assurances for human and environmental health, the US is poised to realize significant economic benefits from improved GE crop variety and yield in the agricultural sector (BIFAD, IFPRI, and APLU 2019). The country grows the largest acreage of GE crops in the world ( $40 \%$ of the global total), and is a net exporter of agricultural products, particularly to developing countries (BIFAD, IFPRI, and APLU 2019). Additionally, due to its market share, the US also houses much of the world's GE crop research.

Despite the enormous potential benefits, the development of GE crops in the US has not been able to reach its full potential (James 2014), largely due to the onerous and speculative commercialization process (Qaim 2009). The entire process of developing a single GE crop in the US is very costly, averaging $\$ 130$ million for 6 years of research and development and 7 years for regulatory review and commercialization (Smyth, McDonald, and FalckZepeda 2013). Furthermore, uncertainty regarding time delays in the complicated regulatory process causes financial burden on companies that consequently limits their investment decisions (Smyth, McDonald, and Falck-Zepeda 2013). For example, the delay in approval by a single year is estimated to cost a biotechnology firm $\$ 22.7$ million (Smyth, McDonald, and Falck-Zepeda 2013).

High barriers to market entry have excluded small and nascent businesses while also limiting commercial attention to only the largest of market opportunities, neglecting crops with lower market share which could benefit greatly from innovation (Schmidt, Belisle, and Frommer 2020; Potrykus 2010). Due to the high up-front costs and uncertain time horizon for returns on investment, GE research has thus far focused on staple crops like corn and wheat. However, the US exports a much larger variety of crops - in California alone, the grape, almond, and pistachio markets are significant contributors to the state's multibillion-dollar agriculture economy (Kuzma 2018).
Issues around the regulation of GE plants have been highlighted by the proliferation of new, cheaper geneediting techniques that can be applied to these crops and by the rapid expansion of capable developers. Historically, the creation of GE crops has been largely performed by research universities and industrial agriculture companies (Waltz 2019). With new geneediting techniques, however, these tasks are now increasingly undertaken by small- to medium-sized innovators such as start-ups and university research spin-offs targeting specialty crops (Waltz 2019). At this time, regulatory processes have not sufficiently adapted to meet the needs of these new stakeholders.

\section{Existing United States federal regulatory framework}

GE plant regulatory policy is primarily created and implemented by three federal agencies: the Environmental Protection Agency (EPA), the Food and Drug Administration (FDA), and the United States Department of Agriculture (USDA). Their responsibilities regarding GE crops are outlined by the 2017 Update to the Coordinated Framework for the Regulation of Biotechnology (EOP 2017) and the 2019 Executive Order on Modernizing the Regulatory Framework for Agricultural Biotechnology Products (E013874) (EOP 2019). Broadly, the regulatory responsibilities of each agency for GE crops depends on the crop's specific use and method of production: the EPA is responsible for pesticide regulation; the FDA manages food safety, including food produced using biotechnology; and the USDA oversees products of biotechnology that may pose a risk to agricultural plant health (USDA, FDA, and EPA. n.d.).

Here, we focus on the USDA, as it is the agency given the most responsibility by, and has the most up-todate regulatory framework in response to, E013874. Within the USDA, the Animal and Plant Health Inspection Service (APHIS) is the primary office responsible for regulating GE crops and other biotechnology products that may pose a risk to agricultural plant and animal health (USDA, FDA, and EPA. n.d.).

APHIS proposed an updated regulatory policy in June 2019 entitled "Movement of Certain Genetically Engineered Organisms," also referred to as the SECURE rule (APHIS 2019). The subsequent final rule published in May 2020 aims to reduce "regulatory burden for developers of organisms that are unlikely 
to pose plant pest risks" (APHIS 2020). To support this process, APHIS has created a publicly-accessible database containing the results of all completed regulatory status reviews, including each reviewed combination of plant, trait, and mechanism of action (MOA; the way a trait is expressed).

One key element of the new SECURE rule is allowing developers to self-determine exemption for their GE plant (Fig. 1). GE plants are exempted if their genetic modification meets any of the following criteria: (1) it is solely a single base pair substitution or deletion, or (2) it introduces nucleic acid sequences from within or corresponding to sequences within the plant's natural gene pool. GE plants with a plant-trait-MOA combination that are the same as those of modified plants that APHIS has already approved can also be self-exempted, with an option to request written confirmation from APHIS (APHIS 2020).

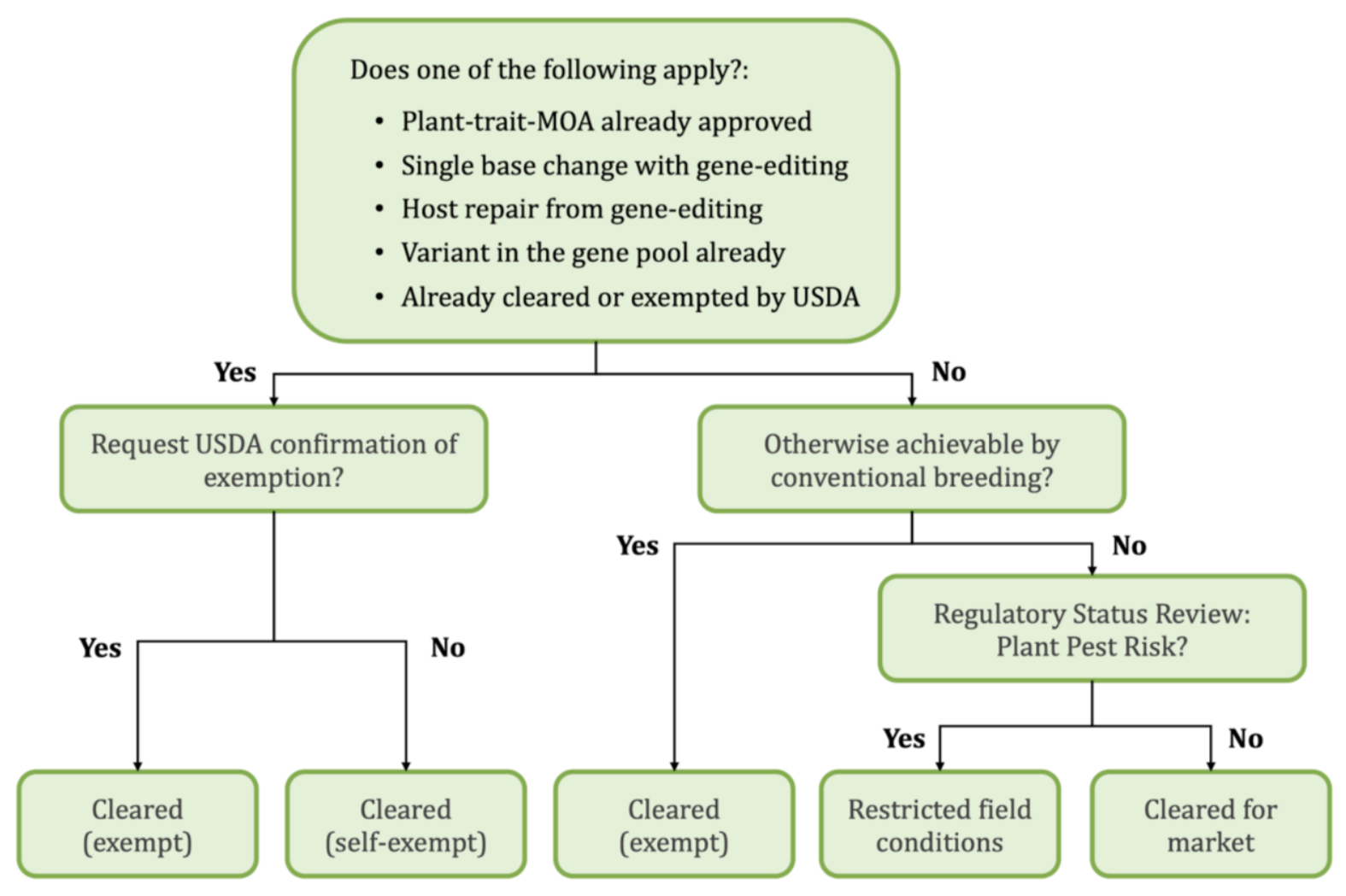

Figure 1: Regulatory pathway described in the 2020 APHIS SECURE rule. Figure adapted from (Kuzma 2020).

To ensure that developers can more easily navigate the regulatory process, E013874 dictates that the USDA, EPA, and FDA must work together to establish a web-based platform providing links to different agency regulatory information (EOP 2019). This was meant to allow developers to submit inquiries and receive guidance through a centralized platform.

While these recent federal actions have sought to clarify and modernize regulation, significant barriers to scaling up the production of GE products still exist. Together, the 2017 Coordinated Framework Update, E013874, and the SECURE rule outline the need for a unified and straightforward process for the approval of new biotechnologies, but the specific details of such a process are weakly defined at present. Given the rapidly changing landscape of agricultural genetic engineering and the entrance of small stakeholders targeting specialty crops, new policies must be implemented that are nimble enough to evolve alongside scientific advancements while balancing the needs of developers and public safety.

\section{Policy recommendations}

Two concrete measures can be taken by the USDA to address the aforementioned shortcomings and provide a clear path to safely and efficiently bring GE crops to market. 
i. Facilitate application submissions through a webbased platform

The federal government, led by the USDA, should implement a clarifying web-based platform that facilitates product approval applications. E013874's recommended Unified Biotechnology Web-Based Platform provides the foundation for improvement but does not go far enough. The platform should contain more than just descriptions for the regulatory roles of the USDA, FDA, and EPA as it does now (USDA, FDA, and EPA n.d.). The web platform currently states that "[each] regulatory agency has its own specific application procedures" but does little more than offer links to each website (USDA, FDA, and EPA n.d.). While the site also allows users to contact the agencies with questions regarding regulation, a far better use of the platform would be an avenue to submit an application for commercial approval of a biotechnology product. If the goal of the current regulatory modernization is to streamline and clarify the process of GE plant approval, then the unified web platform should serve as a tool to help small- and medium-sized producers begin the process of product approval.

ii. Consolidate communication through a central office The USDA should create an office to consolidate communication with crop developers regarding the GE plant approval process and manage a clearinghouse for inquiries. The SECURE rule, while it is an improvement, fails to simplify the regulatory process in a way that makes it accessible to small- to medium-sized innovators who have no previous experience with regulation but otherwise have the technical expertise and capacity to safely contribute to agricultural innovation. Federal agencies should coordinate their response to inquiries in addition to improvement of the aforementioned unified web platform. Since the USDA is currently the designated funder of the consolidated web-based platform (by E013874), we propose that an office be created within the USDA to: manage communication between the three agencies, developers, farmers, and other stakeholders; determine which agency is most appropriate to regulate each product; and maintain the consolidated online platform. The US Congress has the power to establish this office and appropriate funding to it, in accordance with its existing authority (CRS 2018).

\section{Potential limitations of recommended policies}

If the aforementioned proposals are implemented, the USDA will absorb new roles for the overall efficiency of the regulatory process. However, based on changes made in the recent SECURE rule, we expect the agency will also have a greatly decreased regulatory burden since many new GE crops will be exempt from USDA regulation. Still, the USDA may not have sufficient capacity to handle all new requests. As a result, these proposals must be accompanied by an increase in Congressional appropriations, especially for the new clearinghouse office.

Furthermore, the proposed USDA clearinghouse office will not remedy all coordination issues. The more ambitious alternative to address these challenges would be the creation of a new agency, separate from the USDA, FDA, and EPA, to handle GE crop regulation. This would allow consolidation of communication, reporting, regulation, and policy changes into one agency. However, we do not recommend this for several reasons. First, the three existing agencies focus on different aspects of GE crops and this separation is valuable, allowing agencies to specialize within their areas of expertise. Second, the creation of another agency would be expensive and dramatically expand bureaucracy relative to the creation of a single office within the USDA. Third, the political effort required to create a new agency would be substantially greater than the creation of a new office within an existing Department. While imperfect, the proposed USDA office represents an acceptable and pragmatic approach to feasibly improve coordination.

\section{Conclusion}

We recommend a unified and detailed web platform for commercial approval applications and the consolidation of federal regulatory communication pertaining to genetic engineering technology to the USDA. If implemented, these steps will reduce regulatory burdens on companies and researchers seeking to bring new products to market without changing any safety or consumer protection standards. These proposals will also accommodate smaller firms and researchers who do not have dedicated legal staff or experience with handling federal regulations. These stakeholders will face lower financial and time constraints, which currently present major barriers of entry to the field (Potrykus 2010; EOP 2016; Schmidt, Belisle, \& Frommer 2020). 
With a clearer and more streamlined process, the US could see a proliferation of GE crops. By simplifying the GE regulatory requirements, the process of taking a GE crop to market will be more transparent and navigable for small- to medium-sized companies. Streamlining the information, submission, and communication processes should decrease the time required by developers to bring a GE crop to market, thereby making the process cheaper and more accessible to small stakeholders, including

\section{References}

American Farm Bureau Federation (AFBF). 2019. "Fast Facts About Agriculture \& Food." https://www.fb.org/newsroom/fast-facts.

Department of Agriculture, Animal and Plant Health Inspection Service (APHIS). Proposed Rule. "Movement of Certain Genetically Engineered Organisms." Federal Register 84, no. 109 (June 6, 2019):

26514-26541. https://www.govinfo.gov/content/pkg/FR2019-06-06/pdf/2019-11704.pdf.

Department of Agriculture, Animal and Plant Health Inspection Service (APHIS). Final Rule. "Movement of Certain Genetically Engineered Organisms." Federal Register 85, no. 96 (May 18, 2020): 29790-29838. https://www.govinfo.gov/content/pkg/FR2020-05-18/pdf/2020-10638.pdf.

Board for International Food and Agricultural Development (BIFAD), International Food Policy Research Institute (IFPRI), and Association of Public and Land-Grant Universities (APLU). 2019. "How the United States Benefits from Agricultural and Food Security Investments in Developing Countries: Overview." https://doi.org/10.2499/p15738coll2.133419.

Congressional Research Service (CRS). 2018. Congress's Authority to Influence and Control Executive Branch Agencies. R45442. https://crsreports.congress.gov/product/pdf/R/ R45442.

Executive Office of the President (EOP). "Executive Order on Modernizing the Regulatory Framework for Agricultural Biotechnology Products Declared by Executive Order No.13874 of June 11, 2019." 2019.

https://www.whitehouse.gov/presidentialactions/executive-order-modernizingregulatory-framework-agriculturalbiotechnology-products/. innovators who may find niche markets in editing specialty crops that lag in breeding efficiency.

The US agricultural sector also awaits innovations that will increase adaptation to the worsening threats of climate change, such as fire, drought, and flooding. If federal policy keeps pace with these advancements by streamlining and demystifying regulations, the US will benefit from crops that are more diverse, cheaper, and more resilient.

Executive Office of the President (EOP). "Modernizing the Regulatory System for Biotechnology Products: Final Version of the 2017 Update to the coordinated Framework for Regulation of Biotechnology." 2017. https://obamawhitehouse.archives.gov/sites/def ault/files/microsites/ostp/2017 coordinated fra mework update.pdf.

Executive Office of the President (EOP). "National Strategy for Modernizing the Regulatory System for Biotechnology Products." 2016. https://www.fda.gov/media/102667/download.

James, Clive. "Brief 49: Global Status of Commercialized Biotech/GM Crops: 2014." Global Status of Commercialized Biotech/GM Crops. International Service for the Acquisition of Agri-biotech Applications. 2014. http://www.isaaa.org/resources/publications/b riefs/49/default.asp.

Kuzma, Jennifer. "Regulating Gene-Edited Crops." Issues in Science and Technology, 2018. https://issues.org/regulating-gene-editedcrops/.

Kuzma, Jennifer. "USDA Oversight Past to Present." Genetic Engineering and Society Center. 2020. https://mediasite.wolfware.ncsu.edu/online/Cha nnel/gescenter/watch/dfb1f865e8e84f108a29c915b941 $\underline{16 \mathrm{cc} 1 \mathrm{~d}}$

National Academies of Sciences, Engineering, and Medicine (NAS). "Genetically Engineered Crops: Experiences and Prospects." 2016. https://doi.org/10.17226/23395.

Potrykus, Ingo. "Regulation must be revolutionized." Nature 466, no. 561 (2010). https://doi.org/10.1038/466561a.

Qaim, Matin. "The Economics of Genetically Modified Crops." Annual Review of Resource Economics 1, (June 26, 2009): 665-694. https://doi.org/10.1146/annurev.resource.0507 $\underline{08.144203 .}$. 
Schmidt, Sarah M., Melinda Belisle, and Wolf B. Frommer. "The evolving landscape around genome editing in agriculture." EMBO Reports 21 (2020): e50680. https://doi.org/10.15252/embr.202050680.

Smyth, Stuart J, Jillian McDonald, and Jose Falck-Zepeda. "Investment, Regulation, and Uncertainty." GM Crops \& Food 5, no. 1 (2013): 44-57. https://doi.org/10.4161/gmcr.27465.
USDA, FDA, and EPA. n.d. "The Unified Website for Biotechnology Regulation." https://usbiotechnologyregulation.mrp.usda.gov /biotechnologygov/home.

Waltz, Emily. "With CRISPR and Machine Learning, Startups Fast-Track Crops to Consume Less, Produce More." Nature Biotechnology 37, no. 11 (September 24, 2019): 1251-52. https://doi.org/10.1038/d41587-019-00027-2.

Sarah Hartman is a PhD student in Environmental Science, Policy and Management at the University of California, Berkeley, where she studies sustainability of the global virtual water trade and its resulting impacts on the hydro-social cycle.

Wilson Horner is a PhD Candidate in Plant and Microbial Biology at the University of California, Berkeley, where he researches the fundamental pathways of plant metabolism.

Christopher Jackson is a PhD Candidate in Chemistry at the University of California, Berkeley, where his research focuses on developing nanomaterials tools for sensing and gene delivery in biological environments.

Emma Kovak holds a PhD in Plant Biology from the University of California, Berkeley and works as a Food and Agriculture Analyst at the Breakthrough Institute.

Vetri Velan is a PhD Candidate in Physics at the University of California, Berkeley, where his research focuses on detecting particles of dark matter, a mysterious substance making up 85\% of the matter in the universe. 